\title{
Dietary Management and Genetic Predisposition
}

\author{
Hanne Holbæk Jensen • Lesli Hingstrup Larsen
}

Published online: 7 July 2013

(C) Springer Science+Business Media New York 2013

\begin{abstract}
Today, dietary recommendations are based on recommended daily intake for the general population, and only a few subgroups are considered for additional dietary advice. Nutrigenetics aim to optimize health and prevent disease. Particularly for lifestyle disease, such as obesity, which has increased epidemically worldwide, the investigation of genetic predisposition might help to prevent and treat obesity. Predisposition to obesity includes syndromes, such as Prader-Willi Syndrome (PWS), severe early-onset obesity, such as mutations in the melanocortin 4 receptor (MC4R), and common forms of obesity, such as genetic variation in the fat mass and obesity associated gene (FTO). Several studies have explored gene-diet interactions in obesity, weight loss, and regain, but there is a lack of consistency in the identified interactions. This inconsistency is most probably due to a low-moderate effect size of these interactions, which results in the need for large cohorts or replication between several cohorts. However, with large studies the accuracy of phenotypic characterization also might suffer. Currently, consistent results on nutrigenetics in obesity are limited but investigations of rare mutations, copy number variation, and epigenetics might identify additional genetic contributions to obesity, and the use of omics data with integration of nutrigenetics and nutrigenomics will identify genetic subgroups who will benefit from specific dietary advice to optimize health and prevent disease.
\end{abstract}

Keywords Diet · Mutation · Obesity · Single nucleotide polymorphism (SNP) · Gene-diet interaction · Weight loss · Weight regain

H. H. Jensen · L. H. Larsen

Department of Nutrition, Exercise and Sports, Faculty of Science, University of Copenhagen, Copenhagen, Denmark

\section{H. Larsen $(\bowtie)$}

NEXS, SCIENCE, University of Copenhagen, Rolighedsvej 30, 1958 Frederiksberg C, Denmark

e-mail: lehla@life.ku.dk

\section{Introduction}

At the moment, dietary guidelines are based on nontoxic daily allowance for the general population, and only cluster the population into a few subgroups, such as children or pregnant women, to be given specific or additional dietary recommendations. With increasing knowledge of gene-diet interactions for macronutrients and micronutrients, it will be possible to tailor dietary recommendations for specific subgroups based on their genetic makeup. Today, we already use diets tailored to lessen severe diseases; for example, a phenylalanine-free diet is used for phenylketonuria, which is caused by mutations in the phenylalanine hydroxylase gene leading to higher concentration of phenylalanine in the blood, neurotoxicity, and subsequently mental retardation [1].

The possibility of using nutrigenetics to optimize health and prevent disease also applies to the dietary management of obesity. Obesity prevalence has increased epidemically during the past decades, and in 2008, half a billion adults could be categorized as obese (body mass index [BMI] $\geq 30 \mathrm{~kg} / \mathrm{m}^{2}$ ) [2]. There are several possible contributors to the obesity epidemic, but the main causes are an increase in the availability of energy-dense foods and an increase in sedentary activities, whereas everyday physical activity has declined [3]. Despite these changes in the common obesitypromoting environment, a large proportion of individuals remain lean. This suggests that nonenvironmental factors contribute substantially to the individual obesity susceptibility.

Several theories have been put forward to explain our current obesity epidemic [ $4 \bullet \bullet]$. One of the suggested models is the dual intervention point model that determines our susceptibility by a lower and higher body weight set point between which we will move determined on environmental pressure, whereas the upper limit is dependent on our genetic profile [4••]. This hypothesis is in line with the drifty genotype - a reform of the thrifty genotype - that entails that the genetic variation predisposing to obesity has at one point 
been an evolutionary advantage but without the predator pressure on the upper limit for humans allowing for genetic drift for the upper weight limits [5].

Heritability studies have shown that monozygotic twin pairs are more concordant than dizygotic twin pairs for obesity traits and adoptees are more similar to their biological parents than their adopted parents for obesity degree $[6,7]$. These studies and several other studies of obesity heritability supports a significant heritable component estimated to be relatively high by twin studies and relatively low by family studies, resulting in a general estimate of genetic variation accounting for 40-70 \% of the variance in obesity [4••]. Thus, the current environment explains the high worldwide prevalence of obesity, but genetic variation explains the interindividual differences in obesity susceptibility in the obesogenic environment. Equally, twin studies of underfeeding and overfeeding have shown that the interpair variance is much larger than the intrapair variance, indicating that weight loss and weight regain are both highly influenced by genetic variation [8].

Genetics has moved from linkage studies in large families, assuming cosegregation with the disease, and years spent on fine mapping relevant candidate genes, to candidate gene studies, examining one gene at the time, often only the coding regions, for genetic variation, and on to the hypothesis-free genome-wide association studies (GWAS) testing millions of single nucleotide polymorphisms (SNPs) at the same time. The use of GWAS does not require a link between biological function and the gene, but merely tests SNPs identified by the sequencing of the human genome sequence and construction of the human HapMap [9-11], for frequency among cases and controls. Despite these advances in methods, very few genetic loci or SNPs have been consistently associated with obesity $[12,13]$. This lack of accounting for the estimated heritability by genetic variation in the DNA sequence often is referred to as the "missing heritability." The missing heritability could be due to private relatively rare mutations, copy number variants (CNVs), epigenetic factors, which affect gene transcription without changing the DNA sequence [14], interactions between genes, or interactions between gene and environment [15].

\section{Genetics of Obesity}

The three main forms of obesity attributed to genetics are: syndromic obesity, nonsyndromic or monogenic obesity, and common or polygenic obesity. Syndromic obesity is the combination of extreme obesity, physical dysmorphology, and intellectual disabilities and includes syndromes such as Prader-Willi (15q11.2), Bardet-Biedl (BBS2-15), and Alstrom (2p13.1) [16].

Monogenic obesity often is caused by mutations in genes in the leptin-melanocortin signaling pathway or genes expressed in hypothalamic nuclei [17]. Among these monogenic forms of obesity, the most common is due to mutations that reduce the activity or expression of the melanocortin 4 receptor $(M C 4 R)$ [17], with a frequency of 2-6 mutated alleles per 100 persons with obesity [18-20]. The mutations in the MC4R have been shown to be directly coupled with the molecular function of the receptor in vitro as there is an allele dose effect on ad libitum energy intake [18]. Despite a clear association with obesity, most probably caused by haploinsufficiency, it has been observed that the penetrance of the obesity is dependent on age [20] and for some heterozygous carriers of functional mutations there is still an influence of environmental factors [21]. Other less frequent monogenic forms of obesity include mutations in the leptin $(L E P)$, leptin receptor $(L E P R)$, proopiomelanocortin (POMC), prohormone convertase (subtilisin/kexin-type) 1 (PCSK1), single-minded homologue 1 (SIM1), brain-derived neurotrophic factor $(B D N F)$, neurotrophic tyrosine kinase receptor type 2 (NTRK2), and SH2B adaptor protein 1 (SH2B1) [16].

Treatment opportunities for monogenic obesity, apart from the treatment of leptin-deficient children with recombinant leptin [22], are limited, and only a few studies have examined the response of individuals with monogenic obesity to diet with/without physical activity. Weight loss either with diet alone or with the combination of diet and physical activity was similar for obese individuals with $P O M C$ or $M C 4 R$ and for individuals without mutations in these genes [21, 23, 24]. However, children who had MC4R mutations were less successful in maintaining their weight loss compared with children who did not have MC4R mutations [24]. In addition to dietary management of monogenic obesity, bariatric surgery is a treatment option. Specifically for monogenic obesity in which uncontrolled hyperphagia often is a significant phenotypic manifestation, it is critical to determine the response of mutation carriers to treatment as it is expected that approximately a $5 \%$ fraction of morbidly obese individuals undergoing bariatric surgery are carriers of $M C 4 R$ mutations. One case study has suggested that complete MC4R deficiency might influence long-term weight loss after adjustable gastric banding [25], whereas $M C 4 R$ haploinsufficiency, despite large effects on obesity, does not limit weight loss after Roux-en-Y gastric bypass (RYBG), compared with individuals who do not have $M C 4 R$ mutations [26].

Besides the monogenic obesity cases that were discovered on the basis of mouse models of obesity and the exploration of the leptin-melanocortin pathway [27], it has been hypothesized that since obesity is a common condition, the genetic variation might also be common variants (polygenic obesity). As such polygenic obesity is assumed to be associated with common variants that have small additive or nonadditive effect sizes without a Mendelian pattern of inheritance. Based on the thrifty/drifty gene hypothesis, it is not assumed that all obese individuals have the same combination of 
SNPs, but rather that several genetic changes contributed to evolutionary advances $[4 \bullet \bullet]$.

Genome-wide linkage and candidate gene studies have identified 52 genomic regions associated with obesity, with a minimum of two replications [12]. The two approaches have been largely abandoned after obesity-related SNPs were identified by GWAS. These GWAS have led to the identification of novel obesity-associated genes, such as FTO [28, 29], which would not necessarily have been identified based on its biological function but also has identified loci, such as the $M C 4 R$, that have been previously associated with obesity [30]. The FTO and MC4R SNPs increase BMI with $0.4 \mathrm{~kg} / \mathrm{m}^{2} /$ allele and $0.25 \mathrm{~kg} / \mathrm{m}^{2} /$ allele, respectively, and except from TMEM18 $[31,32]$, they are the two genes that confer the highest increase in BMI [33]. In total, 32 loci have been identified from current GWAS that are robustly associated with obesity, ranging in effect size from 0.05-0.40 BMI units per risk-allele for KCTD15 and FTO, respectively [13, 34, 35].

\section{Dietary Intake and Genetic Predisposition}

A change in taste preference or food intake to energy-dense palatable foods, such as foods rich in fat or sugar, could be one of the mechanisms by which common SNPs increase susceptibility to obesity. In fact, not only do some forms of dietary intake show a moderate heritability but it also has been shown that a significant proportion of the heritability is shared with BMI [36, 37], suggesting that taste preferences or food preferences might be genetically driven and impact the development of obesity.

One of the genes that have been investigated for associations with energy intake is the $M C 4 R$ that in addition to predispose to monogenic obesity, has several SNPs in the proximity of the locus that are associated with common obesity [30,38]. The MC4R rs2229616 is associated with an increased total carbohydrate intake (57 g/day) [39], and the MC4R rs17782313 is associated with increased intake of protein (4.4 g protein/day) in women but not with carbohydrate intake [40], whereas a study of 756 healthy adult twin pairs did not identify significant associations between $M C 4 R$ SNPs and macronutrient intake [41].

Additionally, several studies have investigated whether the strongest GWAS hit for obesity is associated with food preference and energy intake. FTO rs9930609 has been associated with increased fat intake [42] as well as total energy intake (independently of body weight) in children [43]. Likewise in adults, FTO rs9939609 has been associated with an increased intake of fat [44] and a higher intake of dietary protein and energy from fat and lower carbohydrate intake [45]. Similarly, the FTO rs8050136, which is in complete linkage disequilibrium (LD) with rs 9939609 , has been associated with a higher habitual dietary intake of protein [46], and FTO rs1421085, which is in LD with rs9939609 $\left(r^{2}=0.97\right)$, with a higher energy percent from fat $(0.5 \mathrm{E} \% /$ allele $)[47 \bullet]$. On the contrary, several studies have not identified any association between FTO SNPs and macronutrient intake [41, 48-50]. The fact that some studies do not identify associations between FTO and macronutrient intake could reflect a requirement for large samples sizes due to small effect sizes. This is highlighted by a recent genome-wide association meta-analysis that investigated associations between SNPs and macronutrient intake in 37,537 individuals, with replication in two additional cohorts of 7,724 and 33,533 individuals, which confirmed the association of FTO rs1421085 (in high LD with rs9939609, $\mathrm{r}^{2}>0.97$ ) with a $0.1 \%$ higher protein intake [51•].

In addition to the FTO and $M C 4 R$, a few other obesityassociated genes have been associated with dietary macronutrient intake. SH2B1 rs7498665 is associated with increased intake of fat $(1.1 \mathrm{~g} / \mathrm{d} / \mathrm{G}$-allele $)$ and saturated fatty acids (SFA, $0.6 \mathrm{~g} / \mathrm{d} / \mathrm{G}$-allele) [52]. $B D N F$ rs6265 is associated with an increased energy intake of $100 \mathrm{kcal} /$ day/allele and $T N N I 3 K$ rs 1514176 was associated with a lower percentage intake of dietary protein of $0.3 \mathrm{E} \% /$ allele [47 $]$. Additionally, there are some indication that rs 35874116 in one of the sweet taste receptors TASIR2 is associated with less carbohydrate intake, including sugars and fibers [53].

The studies of food preference and dietary intake suggest that previously identified obesity-associated GWAS hits could account for some of the shared heritability between obesity and dietary intake but also indicate that additional genetic variation related to taste perception could contribute to this shared heritability.

\section{Genetic Variation and Dietary Management}

In addition to food preference, several physiological mechanisms are involved in determining energy balance, including appetite, absorption, metabolism, and energy expenditure. Previous candidate gene studies have identified several genes involved in energy expenditure, appetite control, and lipid metabolism to influence the response to weight loss, with and without interaction with diet or lifestyle [54-56]. Of these candidate genes, the PPARG Pro12Ala (rs1801282) has been thoroughly investigated $[57,58]$. In the Diabetes Prevention Program (DPP) that includes 2,234 individuals with overweight or obesity and impaired glucose tolerance (IGT) rs1801282 was associated with weight loss after 6months $(-0.63 \mathrm{~kg} /$ allele $)$ and after 2 years $(-0.93 \mathrm{~kg} /$ allele $)$ [59], and in 1,465 individuals on a Mediterranean diet, PPARG rs 1801282 interacted with dietary fat in determining obesity and weight loss [60]. Similarly to the $P P A R G$, the apolipoprotein A-II (APOA2) rs5082 interacts with diet to 
modify weight loss success, which has been shown consistently in 6 independent studies including more than 10,000 individuals $[61,62]$.

In the post-GWAS era, gene-diet interaction analyses have mostly focused on selecting the SNPs that are associated with obesity in GWAS to explore these in a single SNP fashion or by a modified candidate gene approach, including SNPs identified from GWAS and/or additional SNPs from relevant biological candidate genes, trying to select for genediet interactions with a moderate effect size.

For the single gene/SNP studies, it has been most consistently shown that the effect of FTO on obesity can be attenuated by physical activity [63]. In addition to an interaction with physical activity, it also has been shown that high intakes of saturated fatty acids (SFA) interact with FTO rs9930609 to accentuate the effect on obesity [64, 65], and likewise to interact with energy-adjusted fat intake and carbohydrate intake to determine obesity [45]. In the latter study, it was also shown that low leisure time activity accentuated the association of FTO rs9930609 with obesity. Additionally, it has been shown that FTO rs9939609 is associated with better weight loss on a Mediterranean diet over 3 years [66] and a better weight maintenance after weight loss over 40 weeks [67]. However, several studies have not identified any gene-diet interaction effect on weight management of the FTO SNPs [50, 68-74]. Collectively, the association between FTO SNPs and obesity can be accentuated by an increased preference for energy-dense foods and interaction between FTO and these nutrients, and attenuated by physical activity.

One interesting notion, which could be related to the nonconsistency of findings in the FTO-diet interaction studies, is that FTO rs 9939609 has been reported to be associated with underreporting $[45,70]$. This underreporting could potentially reduce the probability of identifying interactions between FTO and energy-dense foods as this association might reflect a specific underreporting of energy dense and likely "unhealthy" food items [75].

Together with the $F T O$ and $M C 4 R$, the transcription factor 7-like 2 (TCF7L2), which is the gene that has been most consistently associated with type 2 diabetes and confers the highest risk [76], has been investigated for the effect on weight management. TCF7L2 HapA (rs7903146 and rs10885406) interacts with dietary protein to attenuate weight change [77], and TCF7L2 rs7903146 is associated with a smaller 10-week weight loss $(2.8 \mathrm{~kg})$ on a high fat compared to a low fat diet [78]. In addition to these GWAS hits, there are additional single SNP studies that show genediet interaction in regulating weight, including TFAP $2 B$ [79] and GIPR [80].

In the two EU-funded Pan-European projects Nutrientgene interaction in obesity (NUGENOB) and Diet and Genes (DIOGENES), we have explored gene-diet interactions in relation to weight loss and weight regain [81, 82]. In NUGENOB, we examined 42 SNPs in 26 genes for an interaction with fat content of a 10 -week hypocaloric diet on weight loss in 648 participants but found no interactions [82]. In DIOGENES, we used a replication strategy to explore associations of the same SNPs in a large observational study and in a smaller but well-controlled dietary intervention study with detailed phenotypic characterization. In the observational study that included 5,507 cases and controls, one significant diet-SNP interaction was identified among 123 SNPs in 15 hypothalamic genes [83]. The interaction between Neuromedin B (NMB) rs7180849 and glycemic index (GI) increase weight gain $25 \mathrm{~g} /$ year per allele per GI unit. In the intervention study, we selected 69 nutrientsensitive candidate genes and included a total of 651 tagSNP selected to cover the genetic variance of the included genes/loci $( \pm 5 \mathrm{~kb})$ with $\mathrm{LD}\left(\mathrm{r}^{2}\right)=0.7-0.8$ and a minor allele frequency above $5 \%$. We examined the interaction between these 651 tagSNPs and either dietary protein or GI on 6month maintenance of weight, waist, or fat mass after a minimum of $8 \%$ weight loss obtained in 8 weeks on a low-calorie diet (LCD) in 742 individuals [81]. After correction for multiple testing, none of the SNP-diet interaction effects were significant. The inclusion of both an observational and an intervention study to explore gene-diet interactions in DIOGENES was done to replicate initial findings from the observational study in the intervention study on weight regain; however, $N M B$ rs 7180849 did not interact to increase weight regain over 6 months in the intervention study [81].

In the MONICA/KORA study, 7 GWAS SNPs (TMEM18, NEGR1, MTCH2, FTO, MC4R, SH2B1 and KCTD15) were investigated in 12,462 individuals, but for none of the SNPs a significant modification by carbohydrate and fat dietary intake was observed on BMI [84]. In a study of 401 German children and adolescents with obesity, it was observed that out of 10 GWAS SNPs associated with childhood obesity, serologically defined colon cancer antigen 8 (SDCCAG8) rs10926984, rs12145833 and rs2783963 were associated with reduced weight loss during the 1-year lifestyle intervention program [85]. However, attempts to replicate the findings in the abovementioned NUGENOB study with 648 adults on a 10-week hypocaloric diet failed [85]. Similarly there was a lack of replication of interactions for 38 genes and dietary intake between two populations of 1,173 African Americans (1,086 SNPs) and 1,165 Caucasians (897 SNPs) [86].

Combining all 32 GWAS hits for obesity by allele loading showed that having a high number of obesity-associated alleles increased BMI more the higher the intake of sugar-sweetened beverages, while no such association was found with artificially-sweetened beverages [87••]. Recently, a GWAS for dietary fat intake among 598 adolescents identified that the opioid receptor $\mu 1$ (OPRM1) rs 2281617 
was associated with a lower fat intake and lower BMI and with a higher amygdala volume, indicating that the OPRMI can influence reward behaviors through regulation of amygdala volume [88]. This study suggests that not only hypothalamic genes are involved in the regulation of energy intake, but that gene-diet interactions with genes in the mesolimbic system could be relevant to investigate in relation to dietary management in obesity.

The above-mentioned gene-diet interaction studies, although several of them are designed to investigate genediet interactions in weight management, are retrospective. Studies that assign dietary management based on genetic profile are scarce. One published study uses the genetic profile to adjust dietary and physical activity advice based on genotypes for 24 SNPs in 19 genes (from a DTC-genetic profiling company) [89]. The study found that genetic profile-based advice increased weight loss success, compared to following standard dietary advice (73 \% vs. $32 \%$ ). Likewise, reports of a similar study with 5 SNPs in 4 genes increased weight loss success over 6 weeks [90]. However, both of the studies were small, including approximately 50 individuals in the genetic profile group, the participants were not all obese and given that one used 24 SNPs and the other 5 SNPs, it would seem that there is no consistency between them. In addition, all SNPs from GWAS or candidate gene studies with suggestive evidence of an interaction with diet on weight changes were not included [89, 90].

\section{Conclusions and Perspectives}

Despite the fact that the currently published papers on genetic predisposition to obesity only explain very little of the estimated heritability and that only suggestive gene-diet interactions have been identified, several DTC genetic profiling companies offer predictive tests and advice on diet and physical activity for optimal health based solely on the genetic profile [91]. Currently, we cannot predict whether an individual will be obese based on the information from GWAS hits nor does this genetic information add to predictions based on asking simple questions, such as parent or childhood obesity [92]. The only exceptions are monogenic obesity cases where we can predict obesity with a high sensitivity and specificity from rare variants. Likewise, we cannot predict the response of an individual to a particular dietary intervention based on the genetic profile or use the genetic profile of an individual to give personalized nutrition advice on how to lose weight or remain weight stable.

Before we can achieve the ultimate goal of providing dietary recommendations for optimal health to subgroups based on nutrigenetics, we need to be able to show consistent associations between genetic variation and response to dietary components. Presently, the studies are fairly small, even for observational studies, and there is lack of replication between studies. Additionally, current studies are focused on macronutrients [51•] and only a few on the quality of the macronutrients [83] or a specific food product [87••], but the focus might as well be on dietary patterns, micronutrients, or the source and quality of the nutrient. To dissect these contributions to dietary management in obesity, more sensitive tools need to be applied to record dietary intake, other measurements of obesity than the crude use of BMI might be necessary and integration of omics data will be essential [93••]. Likewise, the genetic contribution might be viewed as more complex than just the common disease-common variant approach, used in genetic linkage studies, hypothesis-based biological candidate studies and hypothesis-free genome-wide association studies, which have not offered an explanation of the missing heritability. Current strategies include identification and investigation of mutations with lower frequency or CNVs by sequencing either of the entire genome or of the exome [94, 95•, 96]. Additionally, epigenetic changes [14] and possibly telomere length [97] need to be considered in relation to genetic predisposition to obesity.

In conclusion, genetic predisposition in dietary management is still in its infancy, but further exploration of the genetic architecture and the integration with other omics data will allow for dietary recommendation to additional subgroups defined by genetic profiles to optimize health and prevent disease.

\section{Compliance with Ethics Guidelines}

Conflict of Interest Hanne Holbæk Jensen declares that she has no conflict of interest.

Lesli Hingstrup Larsen is supported by grants from the Lundbeck Foundation, the Danish Dairy Association, CRS Food, the European Union FP7, the Innovative Medicines Initiative (IMI), Arla Foods a.m.b.a., and Rhythm Pharmaceuticals.

Human and Animal Rights and Informed Consent This article does not contain any studies with human or animal subjects performed by any of the authors.

\section{References}

Papers of particular interest published recently have been highlighted as:

- Of importance

•- Of major importance

1. MacDonald A, Rocha JC, van Rijn M, Feillet F. Nutrition in phenylketonuria. Mol Genet Metab. 2011;104(Suppl):S10-8.

2. Finucane MM, Stevens GA, Cowan MJ, et al. National, regional, and global trends in body-mass index since 1980: systematic analysis of health examination surveys and epidemiological studies with 960 country-years and 9.1 million participants. Lancet. 2011;377: 557-67. 
3. McAllister EJ, Dhurandhar NV, Keith SW, et al. Ten putative contributors to the obesity epidemic. Crit Rev Food Sci Nutr. 2009;49:868-913.

4. - Speakman JR, Levitsky DA, Allison DB, et al. Set points, settling points and some alternative models: theoretical options to understand how genes and environments combine to regulate body adiposity. Dis Model Mech. 2011;4:733-45. Excellent review and discussions of hypotheses of gene-environment interactions in obesity.

5. Speakman JR. Thrifty genes for obesity, an attractive but flawed idea, and an alternative perspective: the 'drifty gene' hypothesis. Int J Obes (Lond). 2008;32:1611-7.

6. Stunkard AJ, Foch TT, Hrubec Z. A twin study of human obesity. JAMA. 1986;256:51-4.

7. Stunkard AJ, Sorensen TI, Hanis C, et al. An adoption study of human obesity. N Engl J Med. 1986;314:193-8.

8. Perusse L, Bouchard C. Gene-diet interactions in obesity. Am J Clin Nutr. 2000;72:1285S-90.

9. Lander ES, Linton LM, Birren B, et al. Initial sequencing and analysis of the human genome. Nature. 2001;409:860-921.

10. Venter JC, Adams MD, Myers EW, et al. The sequence of the human genome. Science. 2001;291:1304-51.

11. The International HapMap Project. Nature. 2003;426:789-96.

12. Rankinen T, Zuberi A, Chagnon YC, et al. The human obesity gene map: the 2005 update. Obesity (Silver Spring). 2006;14:529-644.

13. Loos RJ. Genetic determinants of common obesity and their value in prediction. Best Pract Res Clin Endocrinol Metab. 2012;26:211-26.

14. Herrera BM, Keildson S, Lindgren CM. Genetics and epigenetics of obesity. Maturitas. 2011;69:41-9.

15. Zuk O, Hechter E, Sunyaev SR, Lander ES. The mystery of missing heritability: genetic interactions create phantom heritability. Proc Natl Acad Sci U S A. 2012;109:1193-8.

16. Ramachandrappa S, Farooqi IS. Genetic approaches to understanding human obesity. J Clin Invest. 2011;121:2080-6.

17. Farooqi IS, O'Rahilly S. Mutations in ligands and receptors of the leptin-melanocortin pathway that lead to obesity. Nat Clin Pract Endocrinol Metab. 2008;4:569-77.

18. Farooqi IS, Keogh JM, Yeo GS, et al. Clinical spectrum of obesity and mutations in the melanocortin 4 receptor gene. N Engl J Med. 2003;348:1085-95.

19. Larsen LH, Echwald SM, Sorensen TI, et al. Prevalence of mutations and functional analyses of melanocortin 4 receptor variants identified among 750 men with juvenile-onset obesity. J Clin Endocrinol Metab. 2005;90:219-24.

20. Stutzmann F, Tan K, Vatin V, et al. Prevalence of melanocortin-4 receptor deficiency in Europeans and their age-dependent penetrance in multigenerational pedigrees. Diabetes. 2008;57:2511-8.

21. Hainerova I, Larsen LH, Holst B, et al. Melanocortin 4 receptor mutations in obese Czech children: studies of prevalence, phenotype development, weight reduction response, and functional analysis. J Clin Endocrinol Metab. 2007;92:3689-96.

22. Farooqi IS. Monogenic human obesity. Front Horm Res. 2008; $36: 1-11$

23. Santoro N, Perrone L, Cirillo G, et al. Weight loss in obese children carrying the proopiomelanocortin R236G variant. J Endocrinol Invest. 2006;29:226-30.

24. Reinehr T, Hebebrand J, Friedel S, et al. Lifestyle intervention in obese children with variations in the melanocortin 4 receptor gene. Obesity (Silver Spring). 2009;17:382-9.

25. Aslan IR, Ranadive SA, Ersoy BA et al. Bariatric surgery in a patient with complete MC4R deficiency. Int J Obes (Lond) 2010.

26. Hatoum IJ, Stylopoulos N, Vanhoose AM, et al. Melanocortin-4 receptor signaling is required for weight loss after gastric bypass surgery. J Clin Endocrinol Metab. 2012;97:E1023-31.

27. Mountjoy KG. Functions for pro-opiomelanocortin-derived peptides in obesity and diabetes. Biochem J. 2010;428:305-24.
28. Frayling TM. Genome-wide association studies provide new insights into type 2 diabetes aetiology. Nat Rev Genet. 2007; 8:657-62.

29. Scuteri A, Sanna S, Chen WM, et al. Genome-wide association scan shows genetic variants in the FTO gene are associated with obesity-related traits. PLoS Genet. 2007;3:e115.

30. Loos RJ, Lindgren CM, Li S, et al. Common variants near MC4R are associated with fat mass, weight and risk of obesity. Nat Genet. 2008;40:768-75.

31. Willer CJ, Speliotes EK, Loos RJ, et al. Six new loci associated with body mass index highlight a neuronal influence on body weight regulation. Nat Genet. 2009;41:25-34.

32. Thorleifsson G, Walters GB, Gudbjartsson DF, et al. Genome-wide association yields new sequence variants at seven loci that associate with measures of obesity. Nat Genet. 2009;41:18-24.

33. Day FR, Loos RJ. Developments in obesity genetics in the era of genome-wide association studies. J Nutrigenet Nutrigenomics. 2011;4:222-38.

34. McCarthy MI. Genomics, type 2 diabetes, and obesity. N Engl J Med. 2010;363:2339-50.

35. Speliotes EK, Willer CJ, Berndt SI, et al. Association analyses of 249,796 individuals reveal 18 new loci associated with body mass index. Nat Genet. 2010;42:937-48.

36. Martin LJ, Lee SY, Couch SC, et al. Shared genetic contributions of fruit and vegetable consumption with BMI in families 20 y after sharing a household. Am J Clin Nutr. 2011;94:1138-43.

37. Hasselbalch AL, Heitmann BL, Kyvik KO, Sorensen TI. Studies of twins indicate that genetics influence dietary intake. J Nutr. 2008;138:2406-12.

38. Zobel DP, Andreasen CH, Grarup N, et al. Variants near MC4R are associated with obesity and influence obesity-related quantitative traits in a population of middle-aged people: studies of 14,940 Danes. Diabetes. 2009;58:757-64.

39. Pichler M, Kollerits B, Heid IM, et al. Association of the melanocortin-4 receptor V103I polymorphism with dietary intake in severely obese persons. Am J Clin Nutr. 2008;88:797-800.

40. Qi L, Kraft P, Hunter DJ, Hu FB. The common obesity variant near MC4R gene is associated with higher intakes of total energy and dietary fat, weight change and diabetes risk in women. Hum Mol Genet. 2008;17:3502-8.

41. Hasselbalch AL, Angquist L, Christiansen L, et al. A variant in the fat mass and obesity-associated gene (FTO) and variants near the melanocortin-4 receptor gene (MC4R) do not influence dietary intake. J Nutr. 2010;140:831-4.

42. Timpson NJ, Emmett PM, Frayling TM, et al. The fat mass- and obesity-associated locus and dietary intake in children. Am J Clin Nutr. 2008;88:971-8.

43. Cecil JE, Tavendale R, Watt P, et al. An obesity-associated FTO gene variant and increased energy intake in children. $\mathrm{N}$ Engl J Med. 2008;359:2558-66.

44. Lear SA, Deng WQ, Pare G, et al. Associations of the FTO rs9939609 variant with discrete body fat depots and dietary intake in a multi-ethnic cohort. Genet Res (Camb). 2011;93:419-26.

45. Sonestedt E, Roos C, Gullberg B, et al. Fat and carbohydrate intake modify the association between genetic variation in the FTO genotype and obesity. Am J Clin Nutr. 2009;90:1418-25.

46. Ahmad T, Lee IM, Pare G, et al. Lifestyle interaction with fat mass and obesity-associated (FTO) genotype and risk of obesity in apparently healthy U.S. women. Diabetes Care. 2011;34:675-80.

47. • McCaffery JM, Papandonatos GD, Peter I, et al. Obesity susceptibility loci and dietary intake in the Look AHEAD Trial. Am J Clin Nutr. 2012;95:1477-86. The study examines the association of 11 GWAS hits with dietary intake, and identifies that TNNI3K rs1514176 is associated with a lower percentage of energy from protein. Additionally, the study finds associations between several SNPs and intake of specific food groups. 
48. Lappalainen T, Lindstrom J, Paananen J et al. Association of the fat mass and obesity-associated (FTO) gene variant (rs9939609) with dietary intake in the Finnish Diabetes Prevention Study. Br J Nutr 2012, 1-7.

49. Hubacek JA, Pikhart H, Peasey A, et al. FTO variant, energy intake, physical activity and basal metabolic rate in Caucasians. The HAPIEE study. Physiol Res. 2011;60:175-83.

50. Vimaleswaran KS, Angquist L, Hansen RD et al. Association between FTO variant and change in body weight and its interaction with dietary factors: the DiOGenes study. Obesity (Silver Spring) 2012.

51. - Tanaka T, Ngwa JS, van Rooij FJ et al. Genome-wide metaanalysis of observational studies shows common genetic variants associated with macronutrient intake. Am J Clin Nutr 2013. Large genome-wide association (GWA) meta-analysis, with replication in 3 cohorts, of macronutrient intake. The study identifies an association between FTO and protein intake and between FGF21 and higher carbohydrate and lower fat intake.

52. Bauer F, Elbers CC, Adan RA, et al. Obesity genes identified in genome-wide association studies are associated with adiposity measures and potentially with nutrient-specific food preference. Am J Clin Nutr. 2009;90:951-9.

53. Eny KM, Wolever TM, Corey PN, El-Sohemy A. Genetic variation in TAS1R2 (Ile191 Val) is associated with consumption of sugars in overweight and obese individuals in 2 distinct populations. Am J Clin Nutr. 2010;92:1501-10.

54. Deram S, Villares SM. Genetic variants influencing effectiveness of weight loss strategies. Arq Bras Endocrinol Metabol. 2009; 53:129-38.

55. Martinez JA, Parra MD, Santos JL, et al. Genotype-dependent response to energy-restricted diets in obese subjects: towards personalized nutrition. Asia Pac J Clin Nutr. 2008;17 Suppl 1:119-22.

56. Qi L, Cho YA. Gene-environment interaction and obesity. Nutr Rev. 2008;66:684-94.

57. Razquin C, Marti A, Martinez JA. Evidences on three relevant obesogenes: MC4R, FTO and PPARgamma. Approaches for personalized nutrition. Mol Nutr Food Res. 2011;55:136-49.

58. Masud S, Ye S. Effect of the peroxisome proliferator activated receptor-gamma gene Pro12Ala variant on body mass index: a meta-analysis. J Med Genet. 2003;40:773-80.

59. Delahanty LM, Pan Q, Jablonski KA, et al. Genetic predictors of weight loss and weight regain after intensive lifestyle modification, metformin treatment, or standard care in the Diabetes Prevention Program. Diabetes Care. 2012;35:363-6.

60. Garaulet M, Smith CE, Hernandez-Gonzalez T, et al. PPARgamma Pro12Ala interacts with fat intake for obesity and weight loss in a behavioural treatment based on the Mediterranean diet. Mol Nutr Food Res. 2011;55:1771-9.

61. Corella D, Peloso G, Arnett DK, et al. APOA2, dietary fat, and body mass index: replication of a gene-diet interaction in 3 independent populations. Arch Intern Med. 2009;169:1897-906.

62. Corella D, Tai ES, Sorli JV, et al. Association between the APOA2 promoter polymorphism and body weight in Mediterranean and Asian populations: replication of a gene-saturated fat interaction. Int J Obes (Lond). 2011;35:666-75.

63. Kilpelainen TO, Qi L, Brage S, et al. Physical activity attenuates the influence of FTO variants on obesity risk: a meta-analysis of 218,166 adults and 19,268 children. PLoS Med. 2011;8:e1001116.

64. Corella D, Arnett DK, Tucker KL, et al. A high intake of saturated fatty acids strengthens the association between the fat mass and obesity-associated gene and BMI. J Nutr. 2011;141:2219-25.

65. Phillips CM, Kesse-Guyot E, McManus R, et al. High dietary saturated fat intake accentuates obesity risk associated with the fat mass and obesity-associated gene in adults. J Nutr. 2012;142:824-31.

66. Razquin C, Martinez JA, Martinez-Gonzalez MA, et al. A 3-year intervention with a Mediterranean diet modified the association between the rs9939609 gene variant in FTO and body weight changes. Int J Obes (Lond). 2010;34:266-72.

67. Woehning A, Schultz JH, Roeder E et al. The A-allele of the common FTO gene variant rs9939609 complicates weight maintenance in severe obese patients. Int J Obes (Lond) 2012.

68. Lappalainen TJ, Tolppanen AM, Kolehmainen M, et al. The common variant in the FTO gene did not modify the effect of lifestyle changes on body weight: the Finnish Diabetes Prevention Study. Obesity (Silver Spring). 2009;17:832-6.

69. Dlouha D, Suchanek P, Lanskalanskalanska V, Hubacek JA. Body mass index change in females after short-time life style intervention is not dependent on the FTO polymorphisms. Physiol Res. 2011;60:199-202.

70. Grau K, Hansen T, Holst C, et al. Macronutrient-specific effect of FTO rs9939609 in response to a 10-week randomized hypo-energetic diet among obese Europeans. Int J Obes (Lond). 2009;33:1227-34.

71. Haupt A, Thamer C, Machann J, et al. Impact of variation in the FTO gene on whole body fat distribution, ectopic fat, and weight loss. Obesity (Silver Spring). 2008;16:1969-72.

72. Muller TD, Hinney A, Scherag A, et al. 'Fat mass and obesity associated' gene (FTO): no significant association of variant rs9939609 with weight loss in a lifestyle intervention and lipid metabolism markers in German obese children and adolescents. BMC Med Genet. 2008;9:85.

73. Hertel JK, Johansson S, Sonestedt E, et al. FTO, type 2 diabetes, and weight gain throughout adult life: a meta-analysis of 41,504 subjects from the Scandinavian HUNT, MDC, and MPP studies. Diabetes. 2011;60:1637-44.

74. Sonestedt E, Gullberg B, Ericson U, et al. Association between fat intake, physical activity and mortality depending on genetic variation in FTO. Int J Obes (Lond). 2011;35:1041-9.

75. Lissner L. Measuring food intake in studies of obesity. Public Health Nutr. 2002;5:889-92.

76. Grant SF, Thorleifsson G, Reynisdottir I, et al. Variant of transcription factor 7-like 2 (TCF7L2) gene confers risk of type 2 diabetes. Nat Genet. 2006;38:320-3.

77. Fisher E, Meidtner K, Angquist L, et al. Influence of dietary protein intake and glycemic index on the association between TCF7L2 HapA and weight gain. Am J Clin Nutr. 2012;95:1468-76.

78. Grau K, Cauchi S, Holst C, et al. TCF7L2 rs7903146-macronutrient interaction in obese individuals' responses to a 10 -wk randomized hypoenergetic diet. Am J Clin Nutr. 2010;91:472-9.

79. Stocks T, Angquist L, Banasik K, et al. TFAP2B influences the effect of dietary fat on weight loss under energy restriction. PLoS One. 2012;7:e43212.

80. Qi Q, Bray GA, Hu FB, et al. Weight-loss diets modify glucosedependent insulinotropic polypeptide receptor rs2287019 genotype effects on changes in body weight, fasting glucose, and insulin resistance: the Preventing Overweight Using Novel Dietary Strategies trial. Am J Clin Nutr. 2012;95:506-13.

81. Larsen LH, Angquist L, Vimaleswaran KS, et al. Analyses of single nucleotide polymorphisms in selected nutrient-sensitive genes in weight-regain prevention: the DIOGENES study. Am J Clin Nutr. 2012;95:1254-60.

82. Sorensen TI, Boutin P, Taylor MA, et al. Genetic polymorphisms and weight loss in obesity: a randomised trial of hypo-energetic high- versus low-fat diets. PLoS Clin Trials. 2006;1:e12.

83. Du H, Vimaleswaran KS, Angquist L, et al. Genetic polymorphisms in the hypothalamic pathway in relation to subsequent weight change - the DiOGenes study. PLoS One. 2011;6:e17436.

84. Holzapfel C, Grallert H, Huth C, et al. Genes and lifestyle factors in obesity: results from 12,462 subjects from MONICA/KORA. Int J Obes (Lond). 2010;34:1538-45.

85. Scherag A, Kleber M, Boes T, et al. SDCCAG8 obesity alleles and reduced weight loss after a lifestyle intervention in overweight children and adolescents. Obesity (Silver Spring). 2012;20:466-70. 
86. Edwards TL, Velez Edwards DR, Villegas R, et al. HTR1B, ADIPOR1, PPARGC1A, and CYP19A1 and obesity in a cohort of Caucasians and African Americans: an evaluation of geneenvironment interactions and candidate genes. Am J Epidemiol. 2012;175:11-21.

87. •- Qi Q, Chu AY, Kang JH, et al. Sugar-sweetened beverages and genetic risk of obesity. N Engl J Med. 2012;367:1387-96. Allele-loading of all 32 obesity-associated loci and association with BMI according to intake of sugar-sweetened beverages and artificially-sweetened beverages with replication of the associations in three cohorts.

88. Haghighi A, Melka MG, Bernard M et al. Opioid receptor mu 1 gene, fat intake and obesity in adolescence. Mol Psychiatry 2013.

89. Arkadianos I, Valdes AM, Marinos E, et al. Improved weight management using genetic information to personalize a calorie controlled diet. Nutr J. 2007;6:29.

90. Fenech M, El-Sohemy A, Cahill L, et al. Nutrigenetics and nutrigenomics: viewpoints on the current status and applications in nutrition research and practice. J Nutrigenet Nutrigenomics. 2011;4:69-89.

91. Gorman U, Mathers JC, Grimaldi KA, et al. Do we know enough? Genes Nutr: A scientific and ethical analysis of the basis for genetic-based personalized nutrition; 2013.

92. Loos RJ. Genetics: genome-wide risk profiles - will they change your life(style)? Nat Rev Endocrinol. 2011;7:252-4.
93. •• Chen R, Mias GI, Li-Pook-Than J, et al. Personal omics profiling reveals dynamic molecular and medical phenotypes. Cell. 2012;148:1293-307. The study uses omics data to construct an integrated personal omics profile and suggests that the combination of genetic variation combined with dynamic omics data can contribute to optimise health and predict disease.

94. Abecasis GR, Auton A, Brooks LD, et al. An integrated map of genetic variation from 1,092 human genomes. Nature. 2012;491: $56-65$.

95. - Wheeler E, Huang N, Bochukova EG, et al. Genome-wide SNP and CNV analysis identifies common and low-frequency variants associated with severe early-onset obesity. Nat Genet. 2013;45:513-7. The study investigates SNPs and copy number variants in 1,509 children with extreme obesity. Four new loci are associated with severe obesity (LEPR, PRKCH, PACS1 and RMST), a significant number of rare CNVs are associated with extreme obesity

96. Bochukova EG, Huang N, Keogh J, et al. Large, rare chromosomal deletions associated with severe early-onset obesity. Nature. 2010;463:666-70.

97. Garcia-Calzon S, Gea A, Razquin C et al. Longitudinal association of telomere length and obesity indices in an intervention study with a Mediterranean diet: the PREDIMED-NAVARRA trial. Int J Obes (Lond) 2013. 